\title{
A Review on the Relationship between Bilingualism and Working Memory
}

\author{
Qinyu Liu, Zhujun Liu \\ Graduate School of Humanities and Social Sciences, The University of Melbourne, Melbourne, Australia \\ Email: qinyul1@student.unimelb.edu.au, zhujunl1@student.unimelb.edu.au
}

How to cite this paper: Liu, Q. Y., \& Liu, Z. J. (2021). A Review on the Relationship between Bilingualism and Working Memory. Open Journal of Modern Linguistics, 11, 121-134.

https://doi.org/10.4236/ojml.2021.112010

Received: September 1, 2020

Accepted: March 2, 2021

Published: March 24, 2021

Copyright $\odot 2021$ by author(s) and Scientific Research Publishing Inc. This work is licensed under the Creative Commons Attribution International License (CC BY 4.0).

http://creativecommons.org/licenses/by/4.0/

\begin{abstract}
In the research on individuals' linguistic development, bilingualism has received much attention, because bilingual's cognitive ability is believed to differ from monolingual's. With particular interest on how bilingualism would impact working memory, the authors reviewed the pertinent studies published in the journal of Bilingualism: Language and Cognition in recent three years (2017-2019). 7 out 49 studies were screened out for comparing and analyzed for their research design and results. By carefully reviewing these studies, the authors find bilingualism generally facilitates working memory capacity, especially for the visuospatial component. However, the bilingual advantage in verbal component is still under somewhat debate, and needs further research.
\end{abstract}

\section{Keywords}

Bilingualism, Bilingual Advantage, Working Memory, Systematic Review

\section{Introduction}

Cognitive ability is a vital component in individuals' development and plays a crucial role in one's language acquisition. The past few decades have seen increasing attention given to the comparisons of monolingual's and bilingual's cognitive performance elicited in various tasks. Although a large volume of research has been conducted on the impact of bilingualism on cognition, the existing literature on this issue seems to have little consistency in the field.

To gain a better understanding of the issue and diverse cognitive outcomes in language acquisition, the current work attempts to synthesize some of the recent research on the relationship between bilingualism and cognitive ability, with a limited scope to the impact of bilingualism on working memory in relation to individuals' linguistic development as a focused perspective. The established coding scheme from Adesope, Lavin, Thompson and Ungerleider (2010) is 
adopted in the study to carefully identify possible factors in the research designs that may have affected the consistency of recent research. Methodological features of these studies would be reviewed and discussed in the following sections.

\section{Background}

\subsection{The Effects of Bilingualism on Cognitive Function}

Since Peal and Lambert (1962)'s seminal work in investigating the flawed methodologies of previous bilingual studies, a considerable body of research has been done on the effects of bilingualism on cognitive function (e.g., Miyake \& Friedman, 2012; Dong \& Li, 2015; Patra, Bose, \& Marinis, 2019). Some studies have noted a number of cognitive benefits from bilinguals' cognitive task performances. For instance, bilinguals' rich exposure of two or more languages has been reported to facilitate their performances in executive processing tasks, such as attentional control in linguistic and nonverbal tasks (e.g., Costa, Hernández, \& Sebastián-Gallés, 2008; Emmorey, Luk, Pyers, \& Bialystok, 2008). For tasks of specific linguistic processing, Bialystok, Luk and Kwan (2005) examined monolingual and bilingual children's reading ability in solving decoding and phonological awareness tasks. Findings in their work indicated a bilingual advantage in early reading ability, especially when their languages had a shared writing system. In relation to monolinguals' and bilinguals' phonological awareness, a later study by Singh, Fu, Tay and Golinkoff (2018) also found a bilingual advantage in discerning vowel changes when learning the meaning of a novel word.

However, other studies have also documented controversial evidence in relation to the impact of bilingualism on cognitive function. Somewhat opposed to a bilingual advantage, certain level of negative, null, or mixed effects of bilingualism have been found in various cognitive tasks under different conditions (based on a comprehensive review in Adesope et al., 2010). For instance, a recent longitudinal comprehensive study by Gathercole et al. (2014) specifically looked at monolinguals and bilinguals' performances in three sets of cognitive tasks (card sorting, Simon, and a metalinguistic task). Findings in their study revealed no bilingual advantage in any of the task across bilingual ages (from childhood through adulthood), while some occasional advantage of monolinguals or individuals who were dominant in the language being tested was observed in the study. A later study of monolingual and bilingual children's production of referential expressions (Serratrice \& De Cat, 2018) indicated no evidence for bilingual children as well, but only under the condition that the language proficiency was controlled for the two groups.

Having observed the discrepancy in the existing body of research on the impact of bilingualism on cognitive function, other variables that may have contributed to the different results have been identified and investigated in several studies (e.g., Adesope et al., 2010; Cockcroft, Wigdorowitz, \& Liversage, 2019; Yang \& Yang, 2017). As pointed out by Dong and Li (2015), a variety of factors, including "the bilingual individual's age, age of acquisition, language proficien- 
cy, frequency of language use, and difficulty of the experimental task" (p. 1) were very likely to influence the presence or absence of bilingual advantages in previous literature. Variations in the first language backgrounds have also been reported to have an effect on bilinguals' performance (Adesope et al., 2010; Yang \& Lust, 2007). For instance, Yang and Lust (2007) found a cross-linguistic difference in lexicon and executive attention task performances between Korean as well as Chinese learning children and Spanish learning children, regardless of their bilingual or monolingual status. Gathercole et al. (2014) further stressed the need for much closer scrutiny of the definitions of bilingual (such as early/late, balanced/certain language dominant) used to recruit participants, and of how to carefully control some external variables (such as SES) for similar studies to be comparable. Even with these seemingly problematic design issues having been identified in the existing literature, in what way and to what extent can these variables contribute to bilinguals' and monolinguals' cognitive task performance still remain under investigation (Adesope et al., 2010; Bialystok, Craik, \& Luk, 2012; Gathercole et al., 2014).

\subsection{The Relationship between Working Memory and Bilingualism}

Working memory (WM), which involves a number of underlying cognitive abilities, is arguably considered as one of the most important components of the cognitive functions (Cockcroft et al., 2019; Dong \& Li, 2015; Morales, Calvo, \& Bialystok, 2013). However, research on the relationship between working memory and bilingualism is generally very few (Adesope et al., 2010; Dong \& Li, 2015; Morrison, Kamal, \& Taler, 2019). In regard to the relationship between working memory and bilingualism, two controversial hypotheses have been generally identified in previous comprehensive reviews in the field (e.g., Adesope et al., 2010; Dong \& Li, 2015). First, to process and manage two or more languages at the same time could add more cognitive load on one's working memory, which suggests that there may be a bilingual disadvantage in efficient information processing (Adesope et al., 2010; Lee, Plass, \& Homer, 2006; Van Merrienboer \& Sweller, 2005). In contrast, other researchers believe that the active use of two or more languages could enhance one's working memory capacity, which may result in a bilingual advantage in related task performances (Bialystok et al., 2005; Morrison, Kamal, \& Taler, 2019; Yang \& Yang, 2017).

To probe into this seemingly controversial issue, some studies have taken a closer look at the components of working memory, including verbal and visuospatial storage, as well as verbal and visuospatial processing (Cockcroft et al., 2019; Dong \& Li, 2015; Paap, Johnson, \& Sawi, 2014). Findings in this line of research suggest that the impact of bilingualism on each component of working memory may not be the same, or can sometimes be contradictory. For instance, a comprehensive review of Miyake and Friedman (2012) noted that bilingual advantage was more likely to appear in the processing components of working memory, rather than in the "passive" storage components (p. 8). This observation was later confirmed in Blom, Küntay, Messer, Verhagen and Leseman 
(2014)'s study of bilingual Turkish-Dutch children. In their study, a bilingual advantage was only found in processing task performance, in which a higher level of cognitive demand was required in working memory. Similarly, in a comparison study of bilingual and monolingual adults' working memory by using the Simon task (Bialystok, Craik, Klein, \& Viswanathan, 2004), findings also suggested that only in sufficiently demanded cognitive tasks could there be a discrepancy detected between bilinguals' and monolinguals' working memory.

As the investigation into different components of working memory may lead to different explanations of the relationship between bilingualism and working memory, some studies have further pointed out a task design issue in discussing the discrepancies. To be specific, Valian (2015) noted some degree of 'task impurity' in measuring working memory processing, in that although some tasks are dependent on participants' processing ability, a certain level of storage is inevitably involved in task performances as well (p. 15). To some extent, it is also challenging for researchers to explain what have actually been measured in the tasks. Due to this reason, and in consideration of other external factors that may have contributed to the inconsistency in the body of literature, future systematic replicates and clearly defined variables are still in need in the field.

\subsection{Purpose of the Study}

To address the gap on the paucity of existing research on the relationship between bilingualism and working memory, and to gain a better understanding of this debatable bilingual advantage issue, the current work aims to synthesize some recent research in the last three years by adopting an established coding scheme used in Adesope et al. (2010)'s systematic review and meta-analysis. With a limited scope to the relationship between bilingualism and working memory, in relation to some aspects in linguistic development, the current work only looks at the recent research published in one journal of the field, Bilingualism: Language and Cognition, by using selected criteria as explained in detail in the following section.

The central aim of current study is to ascertain the more plausible one of the two controversial hypotheses to settle this dispute, and push the research on bilingualism and working memory one step further: to pursue the investigation on bilingualism and working memory with a finer lens. To be tested two hypotheses amid controversy are recapped below:

Hypothesis A: to process and manage two or more languages at the same time could add more cognitive load on one's working memory (in favor of bilingual disadvantage)

Hypothesis B: the active use of two or more languages could enhance one's working memory capacity (in favor of bilingual advantage)

\section{Method}

\subsection{Identifying Primary Studies}

A comprehensive and systematic search was conducted in the Bilingualism: 
Language and Cognition journal from the electronic database of ProQuest Central. The primary search was conducted using these terms or combinations thereof: bilingualism, bilingual children, bilingual adult, bilingual adolescents, cognitive function, working memory, executive function, cognitive task. The published date range was limited to the last three years. A total of 49 articles were obtained from the search procedure. Two researchers then carefully reviewed the titles, abstracts, and key words of the articles to decide whether to include in the current work by applying some selection criteria informed by previous studies (Adesope et al., 2010; Dong \& Li, 2015). Full texts of the journal articles were carefully consulted to obtain a complete picture of the detailed methodology used in the studies. Discussion and result sections in relation to the explanation of working memory task, as well as the targeted linguistic development investigated in the study, were also carefully examined to gain a better understanding of findings and implications as demonstrated in each work.

\subsection{Selection Criteria}

After the primary search, studies had to satisfy the following criteria to be included in the present synthesis:

1) The study had to examine the relationship between bilingualism and working memory by conducting some experimental task(s).

2) The study had to have two groups of participants, one experimental group of bilingual speakers, and one control group of monolingual speakers.

3) Bilingual participants were reported to attain a certain level of proficiency in each language to be compared with monolingual participants.

4) The study included sufficient and detailed descriptions of participants, in that background information related to the two groups of participants were well-defined and justified to be comparable, such as SES.

5) The study had a clear presentation of methodology design, including the type of tasks used to measure participants' working memory, and a targeted (or at least relevant) linguistic development aspect to be measured (such as working memory in relation to novel word learning, as in (Singh et al., 2018; Warmington, Kandru-Pothineni, \& Hitch, 2018).

6) The study had to demonstrate clear measured outcomes in its findings, that whether there was some evidence for a bilingual advantage or not or mixed.

Only 7 out of 49 articles remained to be included in the current work for further analysis after the screening.

\subsection{Data Coding}

Informed by previous review works on the impact of bilingualism on cognitive function (Adesope et al., 2010; Dong \& Li, 2015), four main categories of variables were identified and coded in the current work, including study characteristics, research design, outcome measure and effect size, as shown in Table 1 below. Although there were many types of bilingualism found in these studies 
(such as early bilinguals and late bilinguals), not all studies provided detailed information for this to be categorized as a separate variable in the category of study characteristics. Nevertheless, based on the previous screening procedure, participants in these studies all had reached a certain proficiency level in their language(s) prior to each study. Participants were also reported to be comparable in the dimension of working memory task. For some articles that reported multiple studies of cognitive task outcomes, only the one related to working memory was coded in the current work.

\subsection{Reliability of Coding}

To ensure coding reliability, the selected seven primary studies were coded several times until the agreement was reached. Two researchers first independently reviewed the selected journal articles and coded each article according to the above categories. Their coding results were then compared and discussed. Coding differences were resolved through discussions and careful re-investigation of related articles.

\section{Results}

Main features of the study design and findings pertaining to bilingualism and working memory of the coded seven studies were summarized in Table 2. The column presenting the results of these studies demonstrated that except for Patra et al.'s study (2019), people being able to speak two or more languages predominantly outperformed monolingual people in WM capacity, at least in some of the WM components. When we take a closer look at the measurements used in these studies (showed in Table 3) and combined them with their research findings, it was evidenced that uncontroversially bilinguals were at an advantage in the visuospatial component of WM. Even though the bilingual advantage was not consistent across all the components of WM, bilingualism was at least not at a disadvantage.

Table 1. Coding scheme.

\begin{tabular}{ccc}
\hline Main category & Number of variables & Variables \\
\hline Study characteristics & 5 & Author \\
& & Publication year \\
& & Mean age of participants \\
Research design & 2 & L1 language for monolinguals \\
& & Languages for bilinguals \\
Eutcome measure & 1 & Group comparison \\
Effect size & 2 & Linguistic development target \\
& & Monolingual group size
\end{tabular}


Table 2. Summary of coded seven studies.

\begin{tabular}{|c|c|c|c|c|c|c|c|c|}
\hline \multirow{2}{*}{ Study } & \multicolumn{2}{|c|}{ Participants $(n)$} & \multicolumn{2}{|c|}{ Language $(s)$} & \multirow[b]{2}{*}{ Age } & \multirow{2}{*}{$\begin{array}{c}\text { Linguistic } \\
\text { development } \\
\text { target }\end{array}$} & \multirow[b]{2}{*}{ Task type $(s)$} & \multirow[b]{2}{*}{ Results } \\
\hline & Monolingual & Bilingual & Monolingual & Bilingual & & & & \\
\hline $\begin{array}{l}\text { Cockcroft } \\
\text { et al. }(2019)\end{array}$ & 39 & 39 & English & $\begin{array}{c}\text { African } \\
\text { language-English }\end{array}$ & $18-22$ & - & $\begin{array}{c}\text { Verbal } \\
\text { Visuo-spatial }\end{array}$ & Bilingual advantage \\
\hline $\begin{array}{l}\text { Kerrigan, } \\
\text { Thomas, } \\
\text { Bright, \& } \\
\text { Filippi (2017) }\end{array}$ & 30 & 30 & English & Mixed L1s-English 2 & $21-22(\mathrm{M})$ & - & $\begin{array}{c}\text { Verbal } \\
\text { Visuo-spatial }\end{array}$ & $\begin{array}{c}\text { Mixed (at least no } \\
\text { bilingual disadvantage }\end{array}$ \\
\hline $\begin{array}{l}\text { Morrison } \\
\text { et al. (2019) }\end{array}$ & 23 & 21 & English & English-French & $18-30$ & - & Visuo-spatial & Bilingual advantage \\
\hline $\begin{array}{l}\text { Patra et al. } \\
\text { (2019) }\end{array}$ & 25 & 25 & English & Bengali-English & $30-32$ & $\begin{array}{c}\text { Verbal } \\
\text { performance }\end{array}$ & Verbal & No bilingual advantage \\
\hline $\begin{array}{c}\text { Serratrice } \\
\text { \& De Cat } \\
\quad(2018)\end{array}$ & 87 & 87 & English & Mixed L1s-English & $5-7$ & $\begin{array}{l}\text { Referential } \\
\text { expressions }\end{array}$ & Verbal & $\begin{array}{c}\text { Mixed (at least no } \\
\text { bilingual disadvantage }\end{array}$ \\
\hline $\begin{array}{l}\text { Warmington } \\
\text { et al. (2018) }\end{array}$ & 23 & 23 & English & Hindi-English & 23 & $\begin{array}{l}\text { Novel-word } \\
\text { learning }\end{array}$ & $\begin{array}{c}\text { Verbal } \\
\text { Visuo-spatial }\end{array}$ & Bilingual advantage \\
\hline $\begin{array}{c}\text { Yang \& Yang } \\
\quad(2017)\end{array}$ & 25 & 26 & English & Korean-English & $18-32$ & - & $\begin{array}{c}\text { Verbal } \\
\text { Visuo-spatial }\end{array}$ & $\begin{array}{c}\text { Mixed (at least no } \\
\text { bilingual disadvantage }\end{array}$ \\
\hline
\end{tabular}

Table 3. WM tasks.

\begin{tabular}{ccc}
\hline Study & Visuo-spatial & Verbal \\
\hline Morrison, Kamal, \& Taler (2019) & N-back task & Digit Recall \\
Warmington, Kandru-Pothineni, \& Hitch (2018) & Dot Matrix & Nonword Recall \\
& Block Recall & Listening Recall \\
& Odd One Out & Backward Digit Recall \\
Yang \& Yang (2017) & Spatial Recall & Stroop-span task \\
& Stroop-span task & Attention-impeded Stroop-span task \\
Kerrigan, Thomas, Bright, \& Filippi (2017) & Attention-impeded Stroop-span task & Word span task \\
Patra, Bose, \& Marinis (2019) & Change blindness task & Alpha span task \\
& Corsi blocks task & Backward Digit Span task \\
& - & Digit Recall \\
Serratrice \& De Cat (2018) & Dot Matrix & Word Recall \\
& Mazes Memory & Nonword Recall \\
& Block Recall & Listening Recall \\
& Odd One Out & Counting Recall
\end{tabular}

Based on the aforementioned results, it is suggested that Hypothesis A could be rejected at this stage, and Hypothesis $\mathrm{B}$ proved to be the correct one, i.e., bilingualism facilitates individual's working memory. 


\section{Discussion}

Despite certain similar findings were shared by the seven coded studies, the diversity in their methodological framework applied in the investigation on the relationship between bilingualism and working memory was self-evident as well. In this section, some strengths as well as some weaknesses in these studies will be demonstrated revolving around the key constructs in their research method: working memory measurement, participant selection criteria, linguistic development target (if concerned), and the definition of bilingualism.

\subsection{Working Memory Measurement}

As evident from Table 3 various tasks were applied in measuring different components of working memory, which could potentially account for the inconsistency in partial results achieved in these studies. The speculation on this matter is not groundless. By comparing the research results in Table 2 and the WM tasks in Table 3, some interest findings could be obtained. First, for the four studies claiming no bilingual advantage (included in the mixed results), such results were all given to the verbal component of WM. Besides, these WM tasks producing disapproving results against bilingual advantage were all span tasks. Among these four studies, two of them (Patra et al., 2019; Serratrice \& De Cat, 2018) were comparable for they both used the same task: Backward Digit Span Task. Kerrigan et al. (2017)'s study was significantly different from the other three because the span tasks they used belonged to simple span task requiring only verbal storage. Whereas the span tasks applied in the other three studies were complex span task (as opposed to simple span task), drawing on both storage and processing capacity of verbal WM. If the complex span task was to some extent not ideal for mixing two capacity, then Cockcroft et al. (2019)'s and Warmington et al. (2018)'s study offered us a clearer and more detailed lens. The research methods of these two studies were fairly comprehensive for they measured the WM elements (i.e., verbal storage, verbal processing, visuospatial storage, and visuospatial processing) separately and specifically, and each element was test with at least two different tasks, with eight tasks involved in Warmington et al. (2018)'s study and twelve studies finished in Cockcroft et al. (2019)'s. For these two studies, although their overall conclusion was bilingual individuals were at advantage, not every single task supported this conclusion. For instance, in the task of Listening Recall (in Warmington et al. (2018)'s study), the bilingual group did not significantly outperform the monolingual group.

By comparing the measurement of WM in these studies, it is indicated that verbal WM has received the most controversy in the investigation of bilingual advantage. Besides, the research methods themselves are multifarious, which is potentially responsible for the occurrence of non-corresponding research findings.

\subsection{Participant Selection Criteria}

The participant selection of these studies is of great importance for current 
analysis and review, because the topic discussed in this paper-bilingualism is a personal skill or ability. As a result, the people recruited for each study could make great impact on the conclusion that could by drawn. So in this section, some features pertaining to the participants in these studies would be discussed.

Firstly, determining a proper sample size is always a major problem in an empirical study because a small sample size is unpersuasive, and a large sample size means increased complexity. The sample size of the coded seven studies was mostly controlled between 20 to 30 for each participant group, with the smallest sample size at 23 monolinguals vs 21 bilinguals and the largest sample size at 87 monolinguals vs 87 bilinguals. Among these studies, only the study of Warmington et al. (2018) provided the rationale for the determination of their sample size, which was controlled at 23 for each group. If this size was adequate for getting statistically significant results, then the research findings of all the studies analyzed were statistically reliable.

Secondly, participants' language background plays a major role in the investigation of bilingualism, while the role of participants' other background information was not yet ascertained. For the language background, what languages a bilingual speaks is very influential in bilinguals' cognitive ability of working memory, because the findings of Bialystok, Luk, \& Kwan's (2005) have pointed out that the relationship between two languages could influence bilingual's language development in both languages. The closer the two languages are, the easier the literacy could transfer. So, it is supposed that the cognitive demand would reduce for bilinguals in WM tasks with the closeness of two languages increasing, which could be a possible explanation for bilingual advantage. In these seven studies, all the participants of control group were monolingual English native speakers. Whereas the other language(s) mastered by the bilinguals were different across studies, except for English as one language being shared. This heterogeneity in participants' language background made these studies less comparable with each other, but did make the shared conclusion that bilinguals outperformed monolinguals in visuospatial WM more universal. Another noticeable factor was that the bilingual participants in Kerrigan et al. (2017)'s and Serratrice and De Cat (2018)'s study were not literally bilingual, but rather multilingual. While this matter touched on the definition of bilingualism, and would be discussed later. For other personal factors like socioeconomic status (SES), verbal and non-verbal intelligence, etc., some were controlled by some studies but not controlled by others. But whether these variables were statistically controlled or not, there seemed to be no difference in the conclusions. For example, SES and Verbal IQ were found not to be a determinant for participants' performance on verbal processing task in Cockcroft et al. (2019)'s study.

Thirdly, age is one of the inevitable variables that takes a leading role especially in the research on bilingualism, because the onset age of language acquisition is a dominant factor for the language proficiency a bilingual could achieved. In the seven studies, all the bilinguals were reported to have acquired two or more languages early on in life. The most observable difference regarding age 
among these studies was that in Serratrice and De Cat (2018)'s study young bilingualism was investigated, whereas all the rest research was on adult bilingualism. In Serratrice and De Cat (2018)'s test on bilingual effect on referential abilities, the results seemed to indicate a bilingual disadvantage in WM, which was resulted from the lack of control on English (target language) proficiency level of the participants. This seemingly outlier in comparison with other advantage reported studies was due to bilingual children's reduced experience in English. Many previous studies (e.g., Pelham \& Abrams, 2014) have provided evidence that bilingual children usually lag behind the monolingual children in language leaning especially the vocabulary acquisition. With the children growing up to adult bilinguals, they might have more advantages over the monolinguals. It was understandable that the bilingual children's performance in tasks related to verbal WM could be poorer than monolingual children especially for the tasks like the one occurring in Serratrice and De Cat (2018)'s study, because such tasks were in essence not the investigation on WM. Based on this, it could be concluded that young bilinguals like adult bilingual were in line with some previous findings (Blom et al., 2014; Pelham \& Abrams, 2014) indicating an advantage in WM capacity.

Finally, bilingual proficiency is also an influential factor for bilinguals' performance in WM tasks, because it is evidenced that the factors concerning WM are related to language proficiency (Blom et al., 2014; Linck et al., 2014). Among the seven studies, three (Cockcroft, Wigdorowitz, \& Liversage, 2019; Serratrice \& De Cat, 2018; Yang \& Yang, 2017) have investigated the impact of bilingual proficiency on WM. In Yang \& Yang's (2017) study, the bilingual participants were further divided into two groups of dominant bilinguals and balanced bilinguals according to their bilingual proficiency. The dominant language for the dominant bilinguals was English. The findings suggested that different bilingual degrees were helpful for WM in terms of controlled processing, and there seemed to be not too much difference between the performance of dominant bilinguals and balanced bilinguals in WM tasks. Only under the great memory load would balanced bilinguals perform moderately better than dominant bilinguals. While in Serratrice \& De Cat's (2018) study 87 young bilinguals were compared to 87 monolinguals in their WM performance with language proficiency taken into consideration. The largest difference from other studies was that in their study, the question if there was a bilingual advantage in working memory were investigated with young bilinguals. And the results indicated that the monolingual kids outperform the bilingual kids in verbal WM tasks, which was in consistent with researchers' expectation. The disadvantage of young bilinguals in the verbal WM test was because of their lower proficiency in languages compared to monolingual kids. As many studies have proved that young monolinguals would also outperform young bilinguals in vocabulary (e.g., Bialystok et al., 2012). Serratrice and De Cat (2018) also explored the relationship between language proficiency and WM statistically and found that they were significantly correlated. But they further concluded that when language proficiency was controlled for 
bilingual and monolingual children, the bilingual children would perform as well as monolingual children. It is to be noticed that in their study, the bilingualism did not directly influence the working memory; on the other hand, the cause of the bilingual disadvantage in WM was due to the less language proficiency in vocabulary caused by bilingualism.

\subsection{Linguistic Development Target}

In the seven reviewed studies, some has paid attention to the interaction between linguistic development target and bilingual's advantage or disadvantage in WM (Warmington, Kandru-Pothineni, \& Hitch, 2018; Patra, Bose, \& Marinis, 2019; Serratrice \& De Cat, 2018). For example, in Warmington, Kandru-Pothineni and Hitch's (2018) study, they investigated if there was any difference in novel-word learning between bilinguals and monolinguals and to what extent could WM account for the potential difference. Because the working memory was according to Baddeley and Hitch (1974) consisted of verbal and visuospatial mechanisms, the verbal WM has always been explored for its effect on bilinguals' linguistic development. In Warmington, Kandru-Pothineni, and Hitch's study, they proved that bilinguals performed better than monolinguals in WM and in novel-word learning as well, with the advantage in novel-word learning partially (35\%) influenced by bilingual's short-term verbal memory.

\subsection{Bilingualism Definition}

The definition of bilingual has always been controversial, which is a usually neglected factor in the investigation pertaining to bilingualism. There is only one study that clearly demonstrated the definition of bilingualism the researchers adopted (Serratrice \& De Cat, 2018). In their definition, bilingualism was understood broadly as a child who learned Egnlish in the UK schools and exposed to the home language at home or in the community. For the other studies bilingualism's definition could be looked into through the participants' structure in these studies. In the rest studies the bilingual participants were probed for their bilingualism through questionnaires resting on the comparison of the two language's proficiency and the reflection of their language use in life. It seems that these study except for Serratrice \& De Cat's have followed the Bloomfield's (1933, as cited in Kachru, 1980) definition of bilingualism as "native-like control of two languages" from a maximalist perspective. Some have also included the Weinreich's (1953, as cited in Kachru, 1980) definition that bilingualism was the "practice of alternately using two languages". But in the study done by Yang \& Yang (2017), the bilingual participants were further classified into dominant bilinguals and balanced bilinguals, which indicating the non-maximalist perspective on bilingualism. However overall, no difference was noticed between the performance of dominant bilinguals and balanced bilinguals, it was suggested by researchers that with the memory load increasing the balanced bilinguals would outperform the dominant bilinguals even though just moderately. But it still in- 
dicated that the differences in the definition of bilingualism, which is the case in current field, would definitely impact on the conclusions made about bilingualism. So the nonunitary definition is an important factor that cannot be neglect in studies about bilingualism.

\section{Conclusion}

This paper has reviewed the studies regarding bilingualism and working memory in the journal of Bilingualism: Language and Cognition published in recent three years (2017-2019). Seven studies have been found valid in investigating the bilinguals' work memory and analyzed. A systematic analysis and review has been conducted from the perspectives of methodology, participant-related factors, linguistic development target, and definition of bilingualism. Both advantages of bilingualism and no differences between bilingualism and monolingualism in the comparison of working memory have been noticed in these studies. Based on these results, this paper has rejected the hypothesis suggesting that to process and manage two or more languages at the same time could add more cognitive load on one's working memory, but believed that bilinguals were at a disadvantageous position when compared to monolinguals.

\section{Implications for Future Studies}

By closely reviewing seven studies investigating the relationship between bilingualism and working memory and synthesizing their research findings, a preliminary result of the debate about bilingual advantage in WM has been obtained. The conclusion of current paper holds the belief of bilingual advantage and supports the hypothesis that the active use of two or more languages could enhance one's working memory capacity. However, this advantage of bilingualism is only predominantly evident in visuospatial WM capacity, while the support from the research findings upon bilingual performance in verbal element of WM is insufficient. This is why we claimed a preliminary result of the debate has been obtained. Thereby, future studies with interest in investigating the relationship between bilingualism and WM are suggested to pay some attention on the impact of bilingualism on verbal WM. The dichotomy between the WM element of storage and processing also needs more investigation to obtain a clearer picture of the impact of bilingualism on WM.

\section{Conflicts of Interest}

The authors declare no conflicts of interest regarding the publication of this paper.

\section{References}

Adesope, O. O., Lavin, T., Thompson, T., \& Ungerleider, C. (2010). A Systematic Review and Meta-Analysis of the Cognitive Correlates of Bilingualism. Review of Educational Research, 80, 207-245. https://doi.org/10.3102/0034654310368803 
Baddeley, A. D., \& Hitch, G. J. (1974). Working Memory. Psychology of Learning and Motivation, 8, 47-89. https://doi.org/10.1016/S0079-7421(08)60452-1

Bialystok, E., Craik, F. I., \& Luk, G. (2012). Bilingualism: Consequences for Mind and Brain. Trends in Cognitive Sciences, 16, 240-250. https://doi.org/10.1016/j.tics.2012.03.001

Bialystok, E., Craik, F. I., Binns, M. A., Ossher, L., \& Freedman, M. (2014). Effects of Bilingualism on the Age of Onset and Progression of MCI and AD: Evidence from Executive Function Tests. Neuropsychology, 28, 290-304. https://doi.org/10.1037/neu0000023

Bialystok, E., Craik, F. I., Klein, R., \& Viswanathan, M. (2004). Bilingualism, Aging, and Cognitive Control: Evidence from the Simon Task. Psychology and Aging, 19, 290-303. https://doi.org/10.1037/0882-7974.19.2.290

Bialystok, E., Luk, G., \& Kwan, E. (2005). Bilingualism, Biliteracy, and Learning to Read: Interactions among Languages and Writing Systems. Scientific Studies of Reading, 9, 43-61. https://doi.org/10.1207/s1532799xssr0901_4

Blom, E., Küntay, A. C., Messer, M., Verhagen, J., \& Leseman, P. (2014). The Benefits of Being Bilingual: Working Memory in Bilingual Turkish-Dutch Children. Journal of Experimental Child Psychology, 128, 105-119. https://doi.org/10.1016/j.jecp.2014.06.007

Cockcroft, K., Wigdorowitz, M., \& Liversage, L. (2019). A Multilingual Advantage in the Components of Working Memory. Bilingualism: Language and Cognition, 22, 15-29. https://doi.org/10.1017/S1366728917000475

Costa, A., Hernández, M., \& Sebastián-Gallés, N. (2008). Bilingualism Aids Conflict Resolution: Evidence from the ANT Task. Cognition, 106, 59-86. https://doi.org/10.1016/j.cognition.2006.12.013

Dong, Y., \& Li, P. (2015). The Cognitive Science of Bilingualism. Language and Linguistics Compass, 9, 1-13. https://doi.org/10.1111/lnc3.12099

Emmorey, K., Luk, G., Pyers, J. E., \& Bialystok, E. (2008). The Source of Enhanced Cognitive Control in Bilinguals: Evidence from Bimodal Bilinguals. Psychological Science, 19, 1201-1206. https://doi.org/10.1111/j.1467-9280.2008.02224.x

Gathercole, V. C. M., Thomas, E. M., Kennedy, I., Prys, C., Young, N., Viñas-Guasch, N. et al. (2014). Does Language Dominance Affect Cognitive Performance in Bilinguals? Lifespan Evidence from Preschoolers through Older Adults on Card Sorting, Simon, and Metalinguistic Tasks. Frontiers in Psychology, 5, Article No. 11. https://doi.org/10.3389/fpsyg.2014.00011

Kachru, B. (1980). Bilingualism. Annual Review of Applied Linguistics, 1, 2-18. https://doi.org/10.1017/S0267190500000441

Kerrigan, L., Thomas, M. S., Bright, P., \& Filippi, R. (2017). Evidence of an Advantage in Visuo-Spatial Memory for Bilingual Compared to Monolingual Speakers. Bilingualism: Language and Cognition, 20, 602-612. https://doi.org/10.1017/S1366728915000917

Lee, H., Plass, J. L., \& Homer, B. D. (2006). Optimizing Cognitive Load for Learning from Computer-Based Science Simulations. Journal of Educational Psychology, 98, 902-934. https://doi.org/10.1037/0022-0663.98.4.902

Linck, J. A., Osthus, P., Koeth, J. T., \& Bunting, M. F. (2014). Working Memory and Second Language Comprehension and Production: A Meta-Analysis. Psychonomic Bulletin \& Review, 21, 861-883. https://doi.org/10.3758/s13423-013-0565-2

Miyake, A., \& Friedman, N. P. (2012). The Nature and Organization of Individual Differences in Executive Functions: Four General Conclusions. Current Directions in 
Psychological Science, 21, 8-14. https://doi.org/10.1177/0963721411429458

Morales, J., Calvo, A., \& Bialystok, E. (2013). Working Memory Development in Monolingual and Bilingual Children. Journal of Experimental Child Psychology, 114, 187-202. https://doi.org/10.1016/j.jecp.2012.09.002

Morrison, C., Kamal, F., \& Taler, V. (2019). The Influence of Bilingualism on Working Memory Event-Related Potentials. Bilingualism: Language and Cognition, 22, 191-199. https://doi.org/10.1017/S1366728918000391

Paap, K. R., Johnson, H. A., \& Sawi, O. (2014). Are Bilingual Advantages Dependent upon Specific Tasks or Specific Bilingual Experiences? Journal of Cognitive Psychology, 26, 615-639. https://doi.org/10.1080/20445911.2014.944914

Patra, A., Bose, A., \& Marinis, T. (2019). Performance Difference in Verbal Fluency in Bilingual and Monolingual Speakers. Bilingualism: Language and Cognition, 23, 204-218. https://doi.org/10.1017/S1366728918001098

Peal, E., \& Lambert, W. E. (1962). The Relation of Bilingualism to Intelligence. Psychological Monographs: General and Applied, 76, 1-23.

https://doi.org/10.1037/h0093840

Pelham, S. D., \& Abrams, L. (2014). Cognitive Advantages and Disadvantages in Early and Late Bilinguals. Journal of Experimental Psychology: Learning, Memory, and Cognition, 40, 313-325. https://doi.org/10.1037/a0035224

Serratrice, L., \& De Cat, C. (2018). Individual Differences in the Production of Referential Expressions: The Effect of Language Proficiency, Language Exposure and Executive Function in Bilingual and Monolingual Children.

https://doi.org/10.31234/osf.io/w74zk

Singh, L., Fu, C. S., Tay, Z. W., \& Golinkoff, R. M. (2018). Novel Word Learning in Bilingual and Monolingual Infants: Evidence for a Bilingual Advantage. Child Development, 89, e183-e198. https://doi.org/10.1111/cdev.12747

Valian, V. (2015). Bilingualism and Cognition. Bilingualism: Language and Cognition, 18, 3-24. https://doi.org/10.1017/S1366728914000522

Van Merrienboer, J. J., \& Sweller, J. (2005). Cognitive Load Theory and Complex Learning: Recent Developments and Future Directions. Educational Psychology Review, 17, 147-177. https://doi.org/10.1007/s10648-005-3951-0

Warmington, M. A., Kandru-Pothineni, S., \& Hitch, G. J. (2018). Novel-Word Learning, Executive Control and Working Memory: A Bilingual Advantage. Bilingualism: Language and Cognition, 22, 763-782. https://doi.org/10.1017/S136672891800041X

Yang, H., \& Yang, S. (2017). Are All Interferences Bad? Bilingual Advantages in Working Memory Are Modulated by Varying Demands for Controlled Processing. Bilingualism: Language and Cognition, 20, 184-196. https://doi.org/10.1017/S1366728915000632

Yang, S., \& Lust, B. (2007). Cross-Linguistic Differences in Cognitive Effects Due to Bilingualism: Experimental Study of Lexicon and Executive Attention in Two Typologically Distinct Language Groups. Proceedings of 32th Annual Boston University Conference on Language Development (BUCLD), Boston, 2-4 November 2007, 692-703. 